\title{
De-rhamnosylation of Hesperidin to Hesperitin-7-O-Glucoside by Alkali Tolerant $\alpha$-L-rhamnosidase from Fusarium poae MTCC-2086
}

\author{
Sarita Yadav ${ }^{*}$, Dhirendra Kumar, Sudha Yadava and K.D.S. Yadav \\ Department of Chemistry, DDU Gorakhpur University Gorakhpur, \\ Gorakhpur-273009, Uttar Pradesh, India \\ *Corresponding author
}

\section{A B S T R A C T}

\begin{tabular}{|l|}
\hline Ke y w or d s \\
Hesperidin, Fusarium \\
poae, PNPR, $\alpha$-L- \\
Rhamnosidase, L- \\
Rhamnose
\end{tabular}

An alkali tolerant $\alpha$-L-rhamnosidase from the culture filtrate of a fungal strain, Fusarium poae MTCC-2086 has been purified to homogeneity. The procedure involved concentration by ultrafiltration and cation-exchange chromatography on carboxymethyl cellulose. The purified enzyme gave a single protein band corresponding to molecular mass of $51.0 \mathrm{kDa}$ in SDS-PAGE analysis showing that the enzyme preparation was pure. The native PAGE analysis of the purified enzyme also gave single protein band confirming the purity of the enzyme preparation. Using p-nitrophenyl $-\alpha$-L-rhamnopyranoside as substrate, $K_{m}$ and $k_{\text {cat }}$ values of the enzyme were $0.49 \mathrm{mM}$ and $30.4 \mathrm{~s}^{-1}$, respectively. The $p H$ and temperature optima of the enzyme were 10.0 and $55^{\circ} \mathrm{C}$, respectively. The enzyme is stable below $10^{\circ} \mathrm{C}$ and at $p H 10.0$. The energy of activation for thermal denaturation of enzyme determined by Arrhenius plot was $26.06 \mathrm{k} \mathrm{J} \mathrm{mol}^{-1}$. The enzyme hydrolysed hesperidin to L-rhamnose and hesperitin-7-O-glucoside but it did not hydrolyse naringin and rutin.

\section{Introduction}

$\alpha$-L-rhamnosidase (EC.3.2.1.40) derhamnosylates natural glycosides containing terminal $\alpha-\mathrm{L}-$ rhamnose (Manazanaes et al., 2007; Yadav et al., 2010; Zhu et al., 2017). The derhamnosylated natural glycosides are pharmaceutically important bioactive, bioavailable, rare compounds of medicinal and food value (Manazanaes et al., 2007, Manzanares et al., 2003; Lee et al., 2012; Gerstorferova et al., 2012; De-Silva et al., 2013; Valentova et al., 2014; Miyake and Yumoto, 1999; Manzanares et al., 2003). On selective de-rhamnosylation, naringin (4',5,7- trihydroxy flavanone-7-rhamnoglucoside) gives prunin (4',5,7-trihydroxy flavanone-7glucoside) which exhibits enhanced solubility compared to naringin and its aglycon narengenin (4',5,7-trihydroxy flavanone) while maintaining in vitro inhibition of HMGCoA reductase (Chang et al., 2011). The derhamnosylation product of rutin (quercetin-3$\mathrm{O}-\beta$-glucoside) which is an antithrombic drug to treat myocardial ischemia, cerebral hypoxia and ischemic disease due to its nonoxidisable anti inflammatory, anti-mutagenesis, anti viral properties and other pharmaceutical effects (Wang et al., 2015). Isoquercitrin is a key precursor for the enzymatic biosynthesis of, 
enzymatically modified isoquercitrin (EMIQ) which has been approved as a multiple food additive (Valentova et al., 2014, Makino et al., 2009; Masuka and Kuba, 2012; Shimoda and Hamada, 2010). De-rhamnosylation of hesperidin (hesperitin-7-O-rhamnoglucoside) gives hesperetin-7-O-glucoside (scheme 1) which is a rare compound of medicinal value (Shimoda and Hamada, 2010; Celiz et al., 2015). Due to these reason, $\alpha$-Lrhamnosidases are focus of current research interest (Yadav et al., 2013; Rabausch et al., 2014; Bang et al., 2015; Wang et al., 2015; Kumar et al., 2015; O'Neill et al., 2015). Most of $\alpha$-L-rhamnosidase accepts naringin, rutin and hesperidin as the substrates releasing Lrhamnose and the corresponding derhamnosylated products prunin, hesperitin7-O-glucoside and isoquercitrin, respectively. $\alpha$-L-rhamnosidases which de-rhamnosylated selectively only naringin or rutin or hesperidin are rare (Monti et al., 2004). In this communication, the authors report an alkali resistant $\alpha$-L-rhamnosidase from a fungal strain, Fusarium poae MTCC- 2086 (Catalogue of strain, 2000). The fungal strain was isolated by D. Ananthapadmanaban (Catalogue of strain, 2000) and deposit at the Microbial Type Culture Collection (MTCC) and Gene Bank, Institute of Microbial Technology Chandigarh (India). The purified $\alpha$-L-rhamnosidase de-rhamnosylated hesperidin to hesperetin-7-O-glucoside indicating that the enzyme can be used for the preparation of pharmaceutically important, bioavailable, rare compound hesperetin-7-Oglucoside and L-rhamnose from hesperidin. It does not de-rhamnosylate naringin and rutin.

\section{Materials and Methods}

\section{Materials}

Hesperidin, L-rhamnose, naringin, naringenin, rutin, $\quad$-nitrophenyl- $\alpha$-L-rhamnopyranoside and CM cellulose were purchased from Sigma
Chemical Company, St. Louis, (USA). Manganese (II) sulphate, sodium chloride, sodium acetate were from Merck Ltd., Mumbai, (India) and acetic acid, tartaric acids, citric acids succinic acids and other chemicals were from S.D. Fine Chem. Ltd., Mumbai, (India) and were used without further purifications. The chemicals for electrophoresis including the protein molecular weight markers used in the SDSPAGE and native-PAGE analysis were procured from Bangalore GENEI Pvt. Limited Bangalore (India). Bagasse was collected from a local sugarcane juice shop and corn-cob was prepared by buying corn fruit.

\section{The fungal strain}

Ten fungal strains namely $F$. acuminatum MTCC-1983, F. compatum MTCC-2014, F. culmorum MTCC-349and MTCC-2090, F. decemcellulare MTCC-2079,F. ventricosum MTCC-720, $F$. tumidum MTCC-2463, $F$. solani MTCC 2082 and MTCC-3004, F. poae MTCC- 2086 were purchased from MTCC Centre and Gene Bank, Institute of Microbial Technology, Chandigarh (India). These were maintained on agar slants of the media reported for these fungal strains in the literature (Catalogue of strain, 2000). These fungal strains were tested for the secretion of $\alpha$-L-rhamnosidase in the liquid culture growth medium as reported in the literature (Yadav et al., 2012). Only F. poae MTCC- 2086 was found to secrete $\alpha$-L-rhamnosidase and therefore, further studies on $\alpha$-L-rhamnosidase of only this fungal strain was under taken.

\section{Secretion of the enzyme}

The secretion of $\alpha$-L-rhamnosidase by the $F$. poae MTCC-2086 was studied using the method reported in the literature (Yadav et al., 2012). The growth media consisted of water (MilliQ) $1000 \mathrm{~mL}, \mathrm{CaCl}_{2} 1 \mathrm{~g}, \mathrm{MgSO}_{4} .7 \mathrm{H}_{2} \mathrm{O} 3$ g, $\mathrm{KH}_{2} \mathrm{PO}_{4} 20 \mathrm{~g}, \mathrm{~N}\left(\mathrm{CH}_{2} \mathrm{COONa}\right)_{3} 1.5 \mathrm{~g}$, 
$\mathrm{MnSO}_{4} 1 \mathrm{~g}, \mathrm{ZnSO}_{4} .7 \mathrm{H}_{2} \mathrm{O} 0.1 \mathrm{~g}, \mathrm{CuSO}_{4} .5 \mathrm{H}_{2} \mathrm{O}$ $0.1 \mathrm{~g}, \mathrm{FeSO}_{4} .7 \mathrm{H}_{2} \mathrm{O} 0.1 \mathrm{~g}, \mathrm{H}_{3} \mathrm{BO}_{3} 10.0 \mathrm{mg}$, sucrose $40.0 \mathrm{~g}$, ammonium tartrate $8.0 \mathrm{~g}$. One $\mathrm{mL}$ of the spore suspension (spore density $8 \mathrm{x}$ $10^{6}$ spores/mL) from the agar slant were inoculated aseptically into the sterilized liquid culture medium $(20 \mathrm{~mL})$ kept in $100-\mathrm{mL}$ culture flasks. The culture flasks were incubated in B.O.D. (Biological Oxygen Demand) incubator at $25{ }^{\circ} \mathrm{C}$ under the stationary culture conditions. Aliquots of one $\mathrm{mL}$ of the growing liquid culture medium were withdrawn at the regular intervals of 24 $\mathrm{hr}$, filtered through Millex syringe filters $(0.22$ $\mu \mathrm{m})$ and were analyzed for the presence of $\alpha$ L- rhamnosidase activity by the reported method (Romero et al., 1985) described below.

Three sets of $\alpha$-L- rhamnosidase secretion experiments were performed. In the first set, the effects of the presence of sucrose and glucose in the liquid culture medium on the secretion of $\alpha$-L- rhamnosidase were studied keeping the medium with no carbohydrates as the control. In the second set, the effects of the presence of hesperidin, naringin, corncob and bagasse in the liquid culture growth medium containing $4.0 \%$ sucrose on the secretion of $\alpha$ L- rhamnosidase were studied. In the third set, the effects of varying the concentration of hesperidin in the liquid culture growth medium containing sucrose on the secretion of $\alpha$-L- rhamnosidase were studied. The choice of sucrose in the second set of experiments was due to the fact that it was a better enhancer of $\alpha$-L- rhamnosidase secretion in the medium. Similarly, the choice of hesperidin in the third set of experiments was due to the fact that hesperidin was a better enhancer of $\alpha$-L- rhamnosidase secretion in the growth medium. Each experiment was performed in triplicates and the data points were the average of three measurements and the standard deviation was less than 5\%. In all cases, enzyme activity/ $\mathrm{mL}$ of the growth culture medium was plotted against time (days) of the growth of the culture.

\section{Assay of $\alpha$-L-rhamnosidase activity}

The activity of $\alpha$-L-rhamnosidase was assayed using $p$-nitrophenyl- $\alpha$-L-rhamnopyranoside as the substrate (Romero et al., 1985). The reaction solution consisted of $1.0 \mathrm{~mL}$ of 0.2 $\mathrm{mM} \quad$-nitrophenyl- $\alpha$-L-rhamnopyranoside dissolved in $0.5 \mathrm{M}$ sodium phosphate buffer ( $p H$ 10.0) maintained at $50^{\circ} \mathrm{C} .0 .1 \mathrm{~mL}$ of the enzyme extract was added to the solution, 0.1 $\mathrm{mL}$ aliquot was withdrawn immediately and added to $3.0 \mathrm{~mL}$ of $1.0 \mathrm{~N} \mathrm{NaOH}$. $0.1 \mathrm{~mL}$ aliquots were withdrawn at the intervals of 2 min and were added to $3.0 \mathrm{~mL}$ of $1.0 \mathrm{~N} \mathrm{NaOH}$ kept in different test tubes. The samples were maintained at the ambient temperature at least for $10 \mathrm{~min}$ and $\mathrm{A}_{400}$ were measured spectrophotometrically. The molar extinction coefficient value $21.44 \mathrm{mM}^{-1} \mathrm{~cm}^{-1}$ was used for the calculation of the enzyme unit. One unit of enzyme activity was defined as the amount of enzyme required to hydrolyze 1 $\mu \mathrm{mol}$ of the substrate per min under the above assay conditions. UV-Visible spectrophotometer Hitachi (Japan) model U2000 which was fitted with electronic temperature control unit was used for the spectroscopic measurements. The least count of the absorption measurement was 0.001 absorbance unit.

\section{Purification of $\alpha$-L-rhamnosidase}

For the purification of $\alpha$-L-rhamnosidase, the fungus was grown in 15 sterilized $100 \mathrm{~mL}$ culture flasks each containing $20 \mathrm{~mL}$ of liquid culture medium supplemented with $1.0 \%$ hesperidin and $4.0 \%$ sucrose. The maximum activity of $\alpha$-L-rhamnosidase was reached on the third day of the inoculation of fungal spore in the liquid culture growth medium. On third day, the fungal cultures were pooled and the mycelia were removed by filtering the culture 
medium through 4 layers of cheese cloth. The culture filtrate was centrifuged at $10,000 \mathrm{rpm}$ for $40 \mathrm{~min}$ at $4^{\circ} \mathrm{C}$ and supernatant $(700 \mathrm{ml})$ was concentrated to $30 \mathrm{~mL}$ using Amicon Bioseparations Stirred Cell model 8200 and ultrafiltration membrane PM10. It was dialyzed against $0.01 \mathrm{M}$ phosphate buffer $p H$ 7.0 for $24 \mathrm{hr}$. The appropriate condition for the binding of $\alpha$-L-rhamnosidase on CM cellulose was determined experimentally by the reported method (Pharmacia, 1983). The dialyzed enzyme solution was loaded on CMcellulose column of size $2.5 \times 15 \mathrm{~cm}$ equilibrated with $0.01 \mathrm{M}$ phosphate buffer, $p H$ 7.0. The column was washed with the same buffer and $\alpha$-L-rhamnosidase activity was eluted using the linear $0-1.0 \mathrm{M} \mathrm{NaCl}$ gradient in the same buffer $(50 \mathrm{~mL}$ of the buffer +50 $\mathrm{mL}$ buffer containing $1.0 \mathrm{M} \mathrm{NaCl}$ ). $3.0 \mathrm{~mL}$ fractions were collected and analyzed for the $\alpha$-L-rhamnosidase activity (Romero et al., 1985) and for protein concentration (Lowry et al., 1951). The $\alpha$-L-rhamnosidase active fractions were combined and concentrated using sucrose. The purified concentrated enzyme sample $2.8 \mathrm{ml}$ was stored at $4.0^{\circ} \mathrm{C}$ in the fridge.

\section{SDS-PAGE and native PAGE analysis of the purified enzyme}

The homogeneity of the enzyme preparation was checked by SDS-PAGE analysis using the reported method (Weber and Osborn, 1969). The resolving gel was $10 \%$ acrylamide in $0.375 \mathrm{M}$ Tris-HCl buffer $(\mathrm{pH}$ 8.8) and stacking gel was $5 \%$ acrylamide in $0.063 \mathrm{M}$ Tris- $\mathrm{HCl}$ buffer ( $\mathrm{pH}$ 6.8). The electrophoresis buffer was $0.025 \mathrm{M}$ Tris- glycine buffer $(\mathrm{pH}$ 8.5). The gel was run at constant current of 20 $\mathrm{mA}$. The molecular weight markers used were phosphorylase-97.4, bovine serum albumin66.0, ovalbumin-43.0, carbonic anhydrase29.0 , soyabean trypsin inhibitor $20.1 \mathrm{kDa}$ and lysozyme (14.3kDa). The native polyacrylamide gel electrophoresis was done using the reagent kit supplied by Bangalore Genei Pvt. Limited (India). The resolving gel was $8 \%$ acrylamide in $0.39 \mathrm{M}$ Tris- $\mathrm{HCl}$ buffer $(\mathrm{pH} 8.8)$ and the stacking gel was $5 \%$ acrylamide in $0.068 \mathrm{M}$ Tris- $\mathrm{HCl}$ buffer $(\mathrm{pH}$ 6.8). The reference protein solution used in the native-PAGE was a mixture of bovine serum albumin $(66 \mathrm{kDa})$ and ovalbumin $(43.0 \mathrm{kDa})$. Proteins were visualized by silver staining reported in the literature (Weber and Osborn, 1969).

\section{Determination of the enzymatic characteristics}

The $K_{m}$ and $V_{\max }$ values of the purified $\alpha$-Lrhamnosidase for the substrate p-nitrophenyl$\alpha$-L-rhamnopyranoside were determined by measuring the steady state velocity of the enzyme catalyzed reaction at different concentrations of p-nitrophenyl- $\alpha$-Lrhamnopyranoside (from 0.1 to $2.5 \mathrm{mM}$ ) using the reported method (Romero et al., 1985). The $K_{m}$ and $V_{\max }$ values were determined by linear regression analysis of the data points (average of triplicate measurements) of the double reciprocal plots. The $p H$ and temperature optima of the purified enzyme were determined using p-nitrophenyl- $\alpha$-Lrhamnopyranoside as the substrate and measuring the steady state velocity of the enzyme catalyzed reaction in solutions of varying $p H$ from 5 to 13 and varying temperature from 30 to $70^{\circ} \mathrm{C}$, respectively. For $p H$ variation, $0.5 \mathrm{M}$ sodium phosphate buffer of varying $p H$ was used. For testing the $p H$ stability of the enzyme, the enzyme was incubated in the fixed $p H$ solution for $24 \mathrm{hr}$ and its activity was determined after that using the method as mentioned above. The residual activity was plotted against $p H$. For studding the thermal stability of the enzyme, the enzyme sample was incubated at a fixed temperature for one hour and its residual activity was determined using the method as mentioned above. A graph of residual activity 
verses temperatures was drawn. In order to determine the energy of activation for thermal de-naturation of enzyme, the rate constant for the enzyme de-naturation at different temperature were determine by calculating half life time of the de-naturation of the enzyme from the plot of residual activity versus time curve using the equation $\mathrm{k}=0.693 / \mathrm{t}_{1 / 2}$ where $\mathrm{k}$ is the rate constant at a particular temperature and $t_{1 / 2}$ is the time required to reduced the original activity of the enzyme to the half of its original value. The activation energy for the denaturation of the enzyme was determined using Arrhenius equation and plotting $\log \mathrm{k}$ vs. $1 / \mathrm{T}$ according to the equation $\log \mathrm{k}=\log \mathrm{A}-\mathrm{Ea} / 2.303 \mathrm{RT}$, where $\mathrm{A}$ is the frequency factor, Ea is energy of activation, $\mathrm{R}$ is molar gas constant and $\mathrm{T}$ is temperature in ${ }^{\circ}$ Kelvin. The slope of the straight line gave the value of $\mathrm{Ea} / 2.303 \mathrm{R}$ from which Ea, the energy of activation, was determined.

Studies on the enzymatic hydrolysis of hesperidin, naringin and rutin

To a $1.0-\mathrm{mL}$ solution of $0.5 \mathrm{mM}$ hesperidin in $0.5 \mathrm{M}$ sodium phosphate buffer $\mathrm{pH} 10.0$ at 30 ${ }^{\circ} \mathrm{C}$ and $20 \mu \mathrm{L}$ of the purified $\alpha$-Lrhamnosidase stock $(0.52 \mathrm{IU} / \mathrm{mL})$ was added. The reaction solution was left overnight. The release of hesperitin glucoside was detected by thin-layer chromatography using silica gel on glass plates. The mobile phase was solution of butanol/acetic acid/water (40: 11: 29) (v/v) as the mobile phase. The release of L-rhamnose was also detected by thin-layer chromatography using silica gel on glass plates. The mobile phase used was chloroform: methanol mixture 70:30 (v/v). The detection was performed in an iodine chamber. The samples of the products hesperetin glucoside and L-rhamnose were prepared by preparative TLC using the mobile phases mentioned above. The HPLC-mass spectrometric studies were done at
Sophisticated Analytical Instrument Center, CDRI, Lucknow, U.P. India using the equipment Waters UPLC-TQD Mass spectrometer. Enzymatic biotransformation studies for naringin and rutin were also done using the procedure described above for hesperidin. The TLC experiments for these conversions did not show any transformation.

\section{Results and Discussion}

\section{Effects of the inducers on the secretion of $\alpha$ - L-rhamnosidase and purification of the enzyme}

To maximize the secretion of $\alpha$-Lrhamnosidase by $F$. poae MTCC-2086 for the purification of the enzyme, the effects of addition of glucose and sucrose in the liquid culture growth medium on the secretion of $\alpha$ L-rhamnosidase were studied using the medium having no carbohydrate as a control. The results (Figure 1a) clearly established that the presence of sucrose in the liquid culture growth medium was more effective in enhancing the secretion of $\alpha$-L- rhamnosidase. In a further set of experiments, the effects of the presence of naringin, hesperidin, corn cob and bagasse in the liquid culture growth medium containing on the secretion of $\alpha-\mathrm{L}$ rhamnosidase were studied (Figure 1b). The presence of hesperidin in the growth medium was found to be the most effective in the secretion of $\alpha$-L- rhamnosidase. In a further set of experiments (Figure 1c), the effects of varying the concentration of hesperidin in the growth medium containing $4.0 \%(\mathrm{w} / \mathrm{v})$ fixed sucrose on the secretion of $\alpha$-L-rhamnosidase were studied. The maximum secretion of the enzyme was in the presence of $1.0 \%$ of hesperidin. For purifying the enzyme from the culture filtrate, the fungus was grown in the liquid culture growth medium containing $4.0 \%$ sucrose and $1.0 \%$ hesperidin. Since not much is known about the structure and regulation of $\alpha$-L- rhamnosidase gene (Bourbouze et al., 
1976), the reasons for the enhancement in the secretion of $\alpha$-L-rhamnosidase by the presence of hesperidin in the medium cannot be discussed.

The purification procedure for the $\alpha-\mathrm{L}-$ rhamnosidase from the culture filtrate of $F$. poae MTCC-2086 is summarized in table-1 and the elution profile of the enzyme from the CM-cellulose column is shown in Figure 2. The enzyme bound to $\mathrm{CM}$ cellulose equilibrated with $10 \mathrm{mM}$ of sodium phosphate buffer and was eluted by the linear gradient of $\mathrm{NaCl}$ in the concentration range to 0.6 to 0.8 $\mathrm{M}$ of $\mathrm{NaCl}$. About 11-fold purification of the enzyme with $10 \%$ recovery of the activity was achieved using a simple procedure.The activity peak of the enzyme coincided with the major protein peak indicating that the eluted enzyme was relatively pure. The results of SDS-PAGE analysis are shown in Figure 3a in which lane 1 contained the molecular wt. markers, lane 2 contained the purified enzyme. The presence of single protein band in lane 2 indicated that the enzyme was pure. The molecular weight calculated from the SDSPAGE data was $51.0 \mathrm{kDa}$. Figure $3 \mathrm{~b}$ shows the results of native-PAGE analysis of the purified enzyme in which the purified enzyme was loaded in lane 1 and a mixture of bovine serum albumin $(66 \mathrm{kDa})$ and ovalbumin $(43.0$ $\mathrm{kDa}$ ) was loaded in lane 2 . The presence of a single protein band in lane 1 of native-PAGE confirmed the purity of enzyme.

\section{Steady state kinetic parameters}

The Michaelis-Menton constant and the turnover number of the purified enzyme at $50^{\circ} \mathrm{C}$ in $0.1 \mathrm{mM}$ sodium phosphate buffer $\mathrm{pH}$ 10.0 using p-nitrophenyl- $\alpha$-Lrhamnopyranoside as the substrate were calculated from double reciprocal plots (data not shown). The calculated $K_{m}$ value for this enzyme using p-nitrophenyl- $\alpha-1-$ rhamnopyranoside as the substrate was 0.49
$\mathrm{mM}$. The $K_{m}$ values using $p$-nitrophenyl- $\alpha-\mathrm{L}-$ rhamnopyranoside as substrate for $\alpha$-Lrhamnosidases purified from Fagopyrum esculeutum (Jang and Kim, 1996), Bacteroides JY-6 (Miake et al., 2001), Pseudomonas paucimobilis FP 2001 (Park et al., 2005), Fusobacterium K (Manzanares et al., 2001), and Aspergillus aculeatus RhaA and RhaB (Berg et al., 2012) have been reported to be $0.33,0.29,1.18,0.057$ and 0.3 and $2.8 \mathrm{mM}$, respectively. The purified $\alpha$-L-rhamnosidase from $F$. poae MTCC-2086 had intermediate affinity for p-nitrophenyl- $\alpha$-Lrhamnopyranoside as compared to the affinities reported for other $\alpha$-Lrhamnosidases. The calculated $k_{c a t}$ value was $30.42 \mathrm{~s}^{-1}$ giving $k_{\text {cat }} / K_{m}$ value of $6.25 \times 10^{4} \mathrm{M}^{-1}$ $\mathrm{s}^{-1}$. The $\mathrm{k}_{\text {cat }}$ value of this $\alpha$-L-rhamnosidase is in the same ranges the $\mathrm{k}_{\text {cat }}$ values of other fungal $\alpha$-L-rhamnosidases (Yadav et al., 2010). However, this $\mathrm{k}_{\text {cat }}$ value is lower than the $\mathrm{k}_{\mathrm{cat}}$ value of $\alpha$-L-rhamnosidase reported (Lise et al., 2016) for bacterial Novosphingobium sp. PP1Y which is $734.4 \mathrm{~s}^{-1}$ and higher than the $\mathrm{k}_{\mathrm{cat}}$ value of $\alpha-\mathrm{L}$ rhamnosidase reported for the bacterial $\alpha-\mathrm{L}-$ rhamnosidase of Klebsiella oxytoca which is $0.98 \mathrm{~s}^{-1}$. The $\mathrm{k}_{\mathrm{cat}} / \mathrm{K}_{\mathrm{m}}$ value of $6.25 \times 10^{4} \mathrm{M}^{-1} \mathrm{~s}^{-1}$ of the purified $\alpha$-L-rhamnosidases is much smaller in comparison to a perfectly evolved enzyme, the limiting values for which is of the order of $10^{8}-10^{9} \mathrm{M}^{-1} \mathrm{~s}^{-1}$ (Berg et al., 2012). Thus there is a great scope for improving the catalytic efficiency of this enzyme using the technique of directed evolution (Arnol and Georgiou, 2003; Kurosawa et al., 1973).

Effects of $\mathrm{pH}$ and temperature on the activity of the enzyme

The results of the dependence of the activity of the purified enzyme on the variation of the $\mathrm{pH}$ of the reaction solution are shown in Figure 4a. The enzyme was active in the basic $\mathrm{pH}$ range 8-13 but the maximum activity of the enzyme was at $p H 10.0$. 
Table.1 Summary of purification procedure

\begin{tabular}{|lccccc|}
\hline Steps & $\begin{array}{c}\text { Total activity } \\
\text { IU }\end{array}$ & $\begin{array}{c}\text { Total protein } \\
\text { mg }\end{array}$ & $\begin{array}{c}\text { Specific activity } \\
\text { IU/mg }\end{array}$ & Protein fold & \% yield \\
\hline Crude & 67.40 & 21.0 & 3.2 & 1.0 & 100 \\
Amicon Conc. & 64.40 & 16.6 & 3.63 & 1.3 & 96 \\
Dialysis & 28.86 & 3.40 & 8.49 & 2.6 & 43 \\
CM Cellulose & 10.02 & 0.71 & 14.11 & 4.4 & 10 \\
\hline
\end{tabular}

Fig.1 Secretion of $\alpha$-L-rhamnosidase by F. poae MTCC-2086

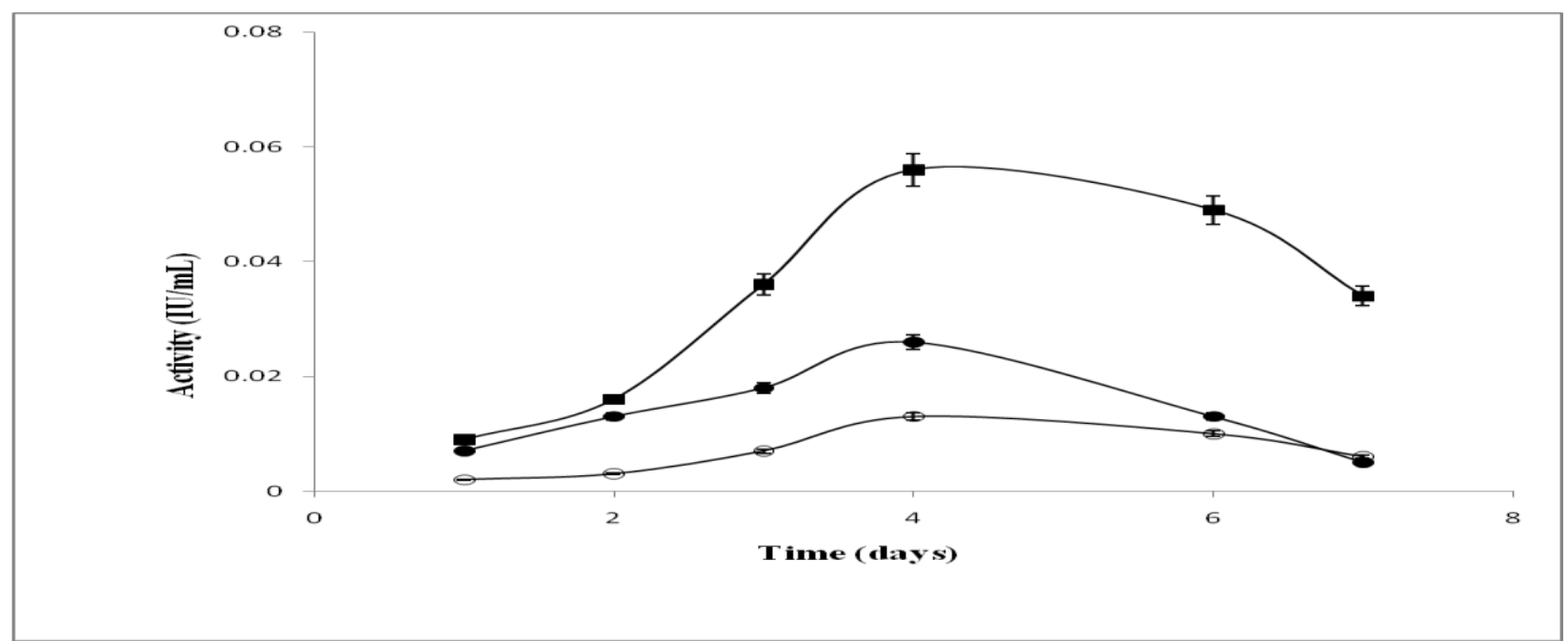

(a) In the culture medium containing $4 \%$ sucrose $(\boldsymbol{\bullet}), 4 \%$ glucose $(\bullet)$ and control (०)

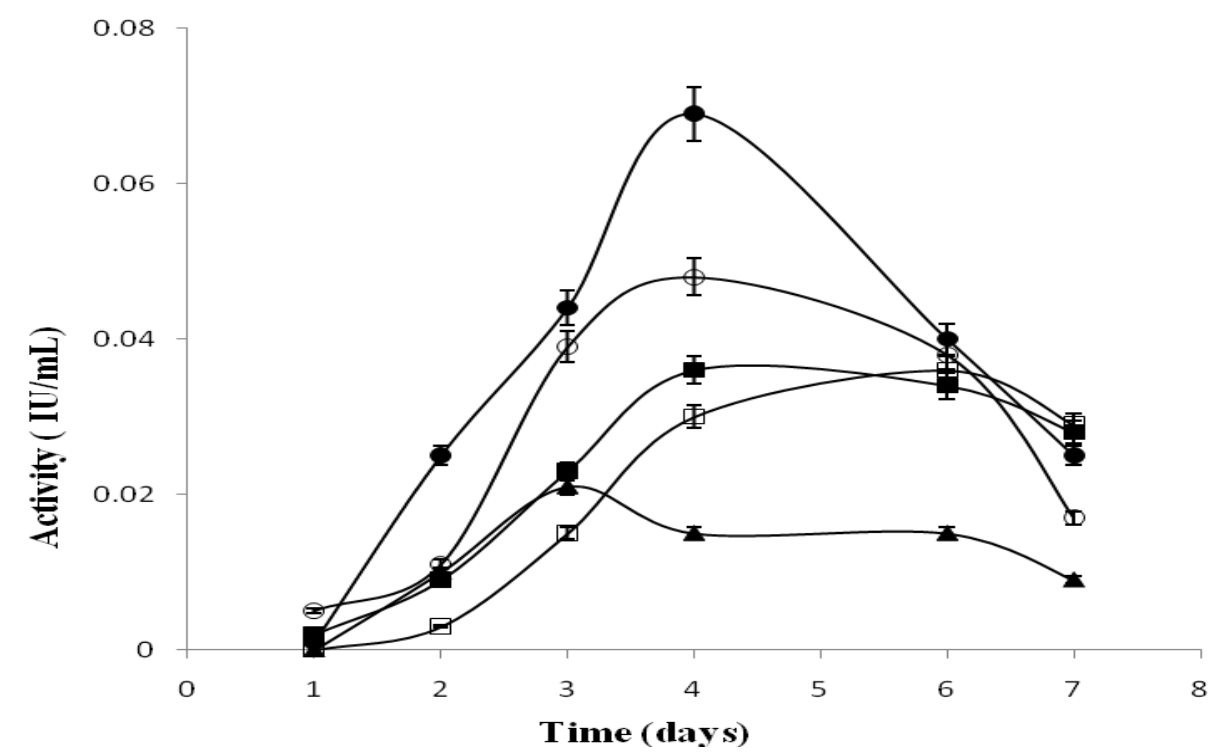

(b) In the culture medium containing $4 \%$ sucrose amended with $0.5 \%$ hesperidin $(\bullet), 0.5 \%$ naringin ( $(\circ), 0.5 \%$ corn cob ( $\mathbf{\square}), 0.5 \%$ bagasse $(\square)$ and control $(\boldsymbol{\Delta})$ 


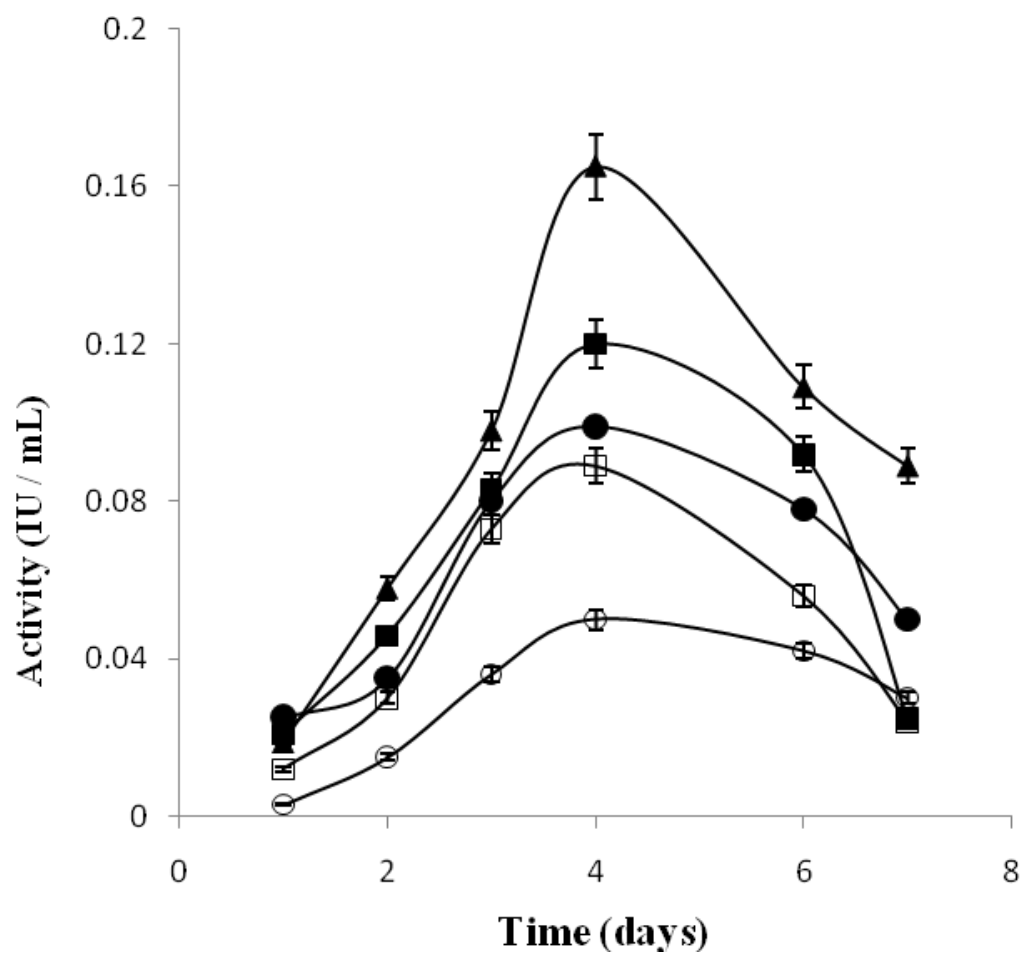

(c) In the culture medium amended with different concentration of hesperidin as inducer, control $(\circ), 0.5 \%(\bullet), 1.00 \%(\mathbf{\Lambda}) 1.25 \%,(\bullet)$ and $1.50 \%$ (口)

Fig.2 Elution profile of $\alpha$-L-rhamnosidase from CM-cellulose column. Protein (•); activity (०); $\mathrm{NaCl}$ gradient (---)

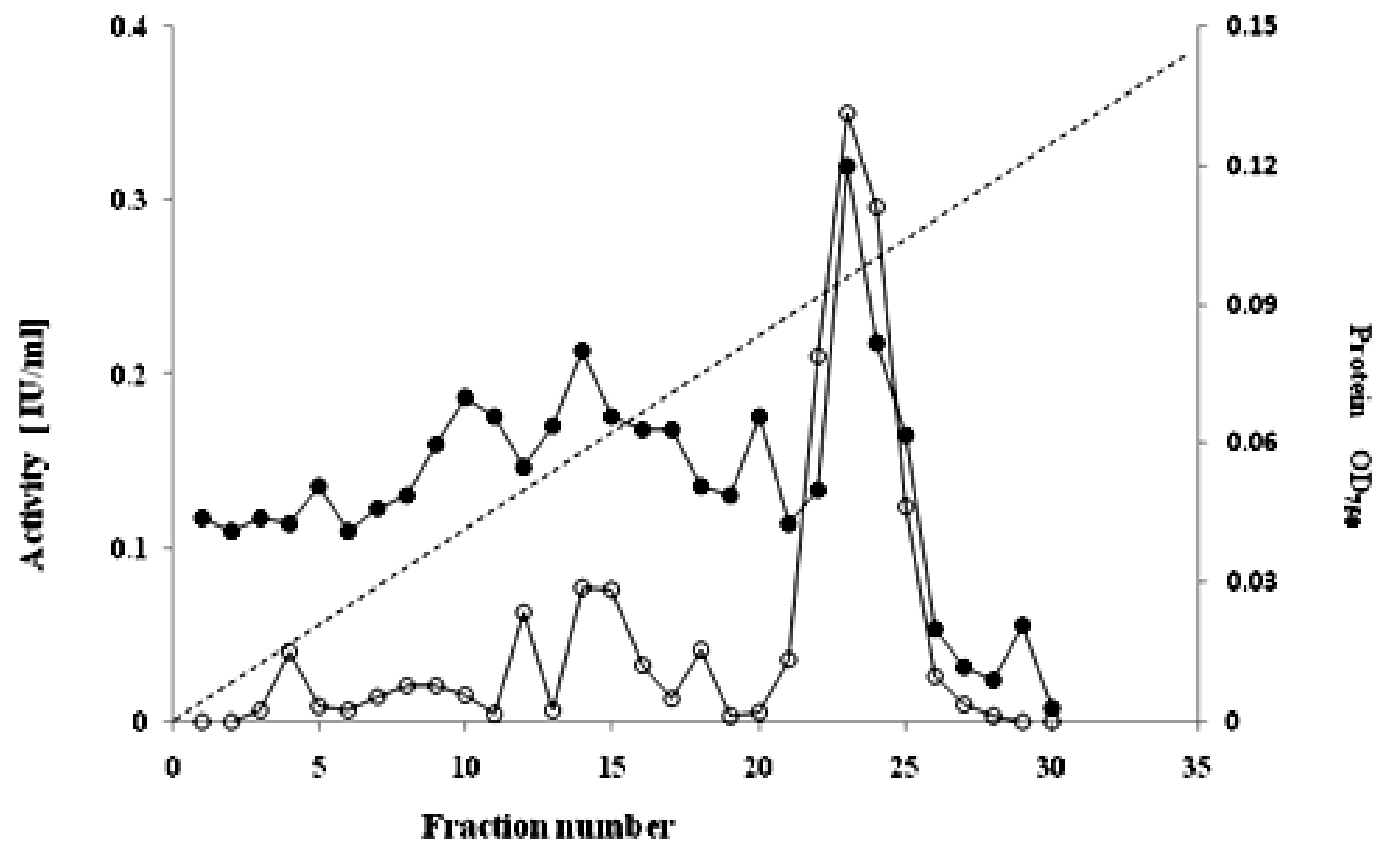


Fig.3 Results of (a) SDS-PAGE and (b) Native- PAGE analysis of purified enzyme: (a) Lane 1 molecular weight markers and lane 2 purified enzyme $0.65 \mu \mathrm{g}$ and lane 3 crude culture filtrate (b) Lane 1 purified enzyme $1.25 \mu \mathrm{g}$ and lane 2 Bovine serum albumin $(66.0 \mathrm{kDa})$ and Ovalbumin $(43.0 \mathrm{kDa}) 5.0 \mu \mathrm{g}$

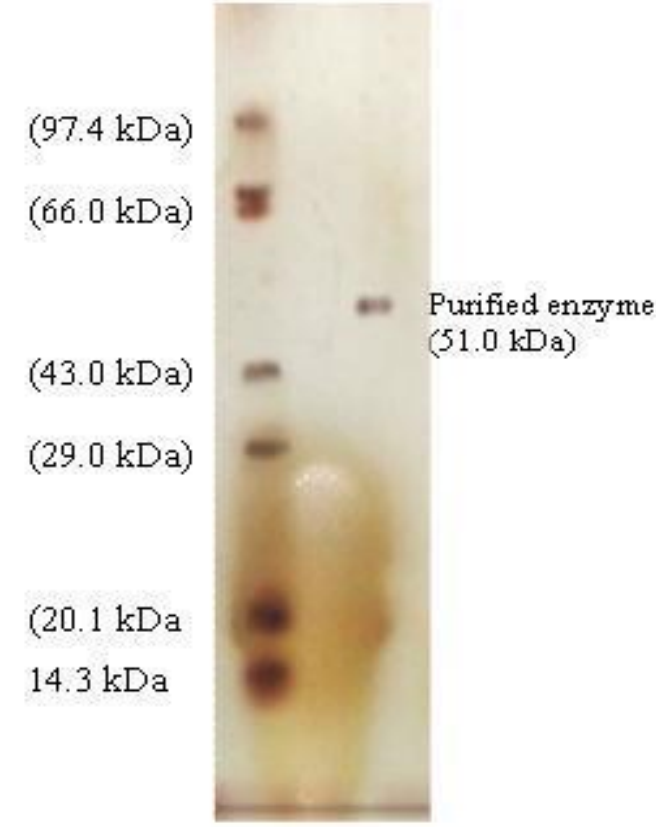

(a) 12

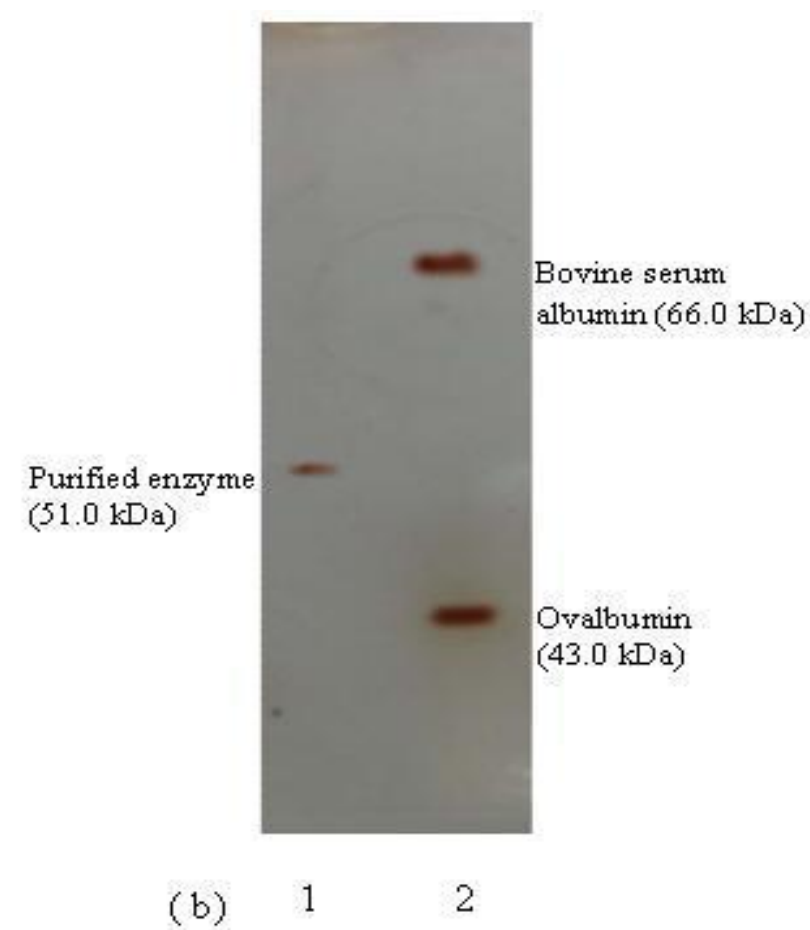

Fig.4 Effects of $\mathrm{pH}$ on the activity of the enzyme. (a) $\mathrm{pH}$ optima (•). The assay solution $1.0 \mathrm{~mL}$ contained $0.4 \mathrm{mM}$ substrate, $1.50 \mu \mathrm{g}$ of the pure enzyme in $0.5 \mathrm{M}$ sodium phosphate buffer of varying $p H$ in the range $5-13$ at $50{ }^{\circ} \mathrm{C}(\mathrm{b}) \mathrm{pH}$ stability (o). The assay solution of varying $\mathrm{pH}$ in the range $7-13$ left overnight at $25^{\circ} \mathrm{C}$ and analyzed for the activity after $24 \mathrm{~h}$

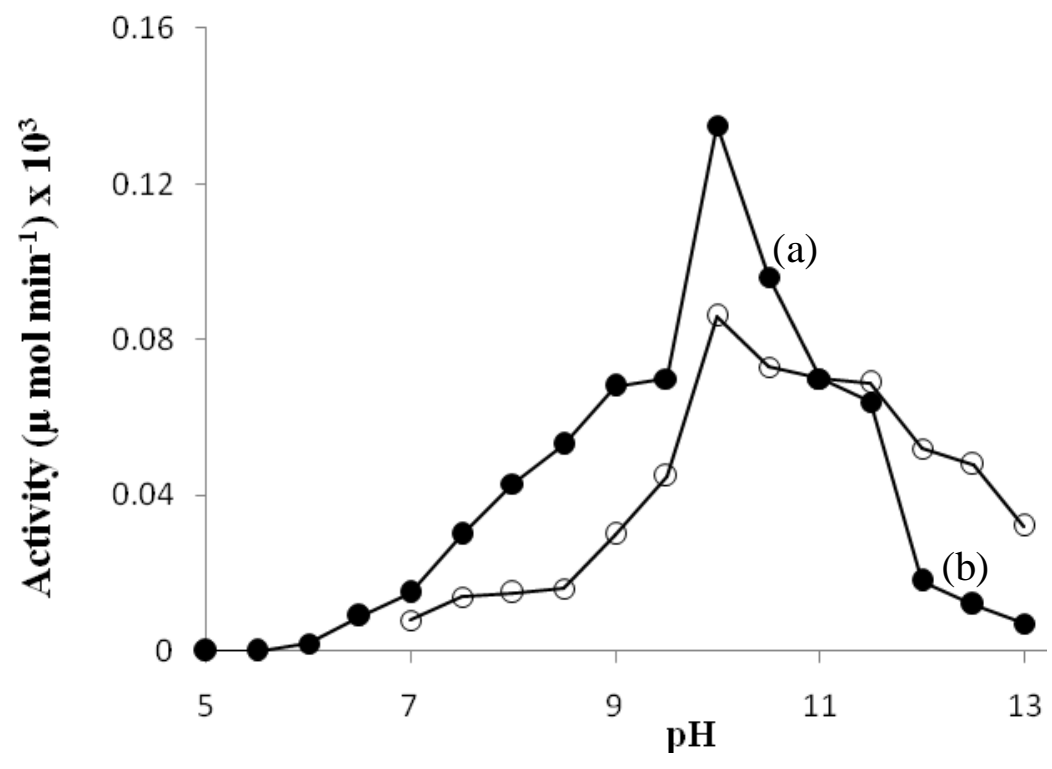


Fig.5 Effects of temperature on the activity of the enzyme. (a) Temperature optima (•). The assay solution $1.0 \mathrm{~mL}$ contained $0.4 \mathrm{mM}$ substrate, $1.50 \mu \mathrm{g}$ of pure enzyme in $0.5 \mathrm{M}$ sodium phosphate buffer $\mathrm{pH} 10.0$ at varying temperatures $\left(30-80^{\circ} \mathrm{C}\right)$. (b) Thermal stability $(\mathrm{O})$. The assay solution at varying temperature $\left(10-80^{\circ} \mathrm{C}\right)$ left at one hour and analyzed for the activity

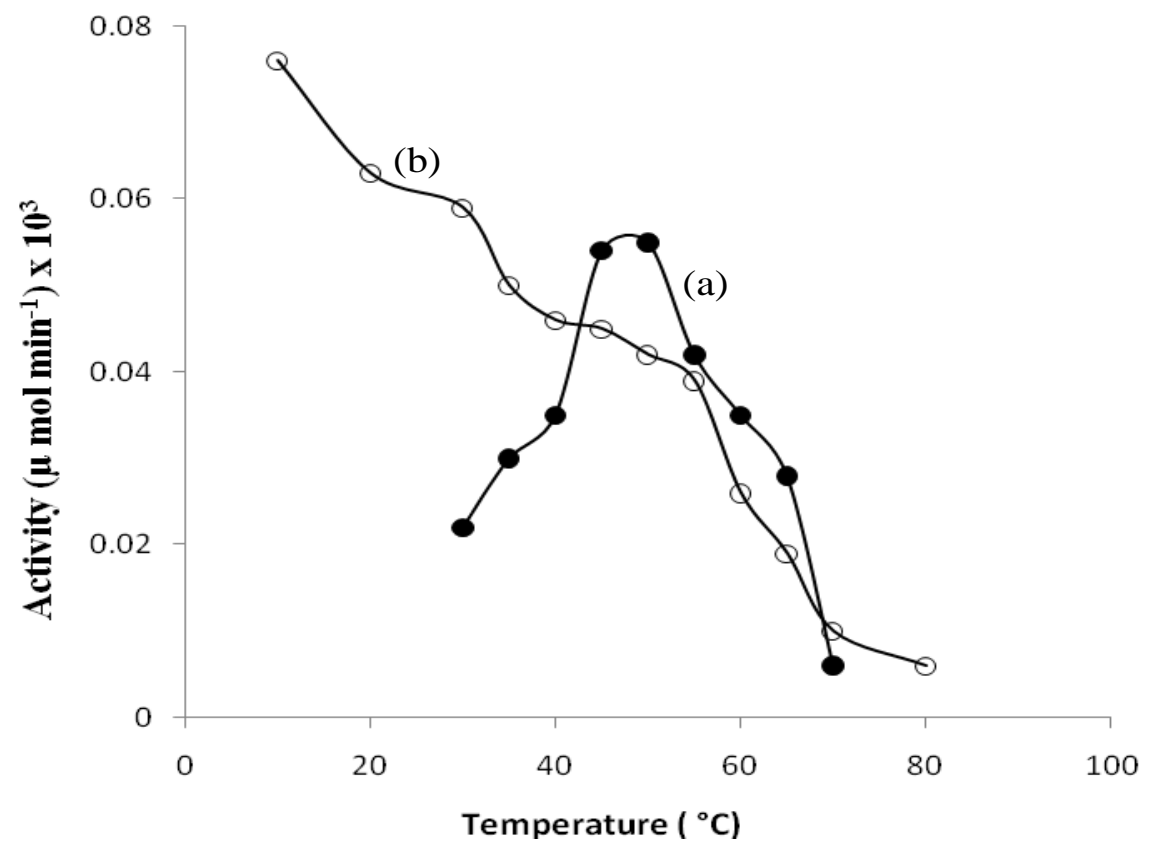

Fig.6 Studies on the release of hesperitin glucoside from hesperidin by the purified enzyme: (a) lane 1 pure hesperidin, lane 2 product of enzymatic hydrolysis of hesperidin and lane 3 pure sample of hesperetin (b) HPLC-MS chromatogram of product of enzymatic hydrolysis of hesperidin

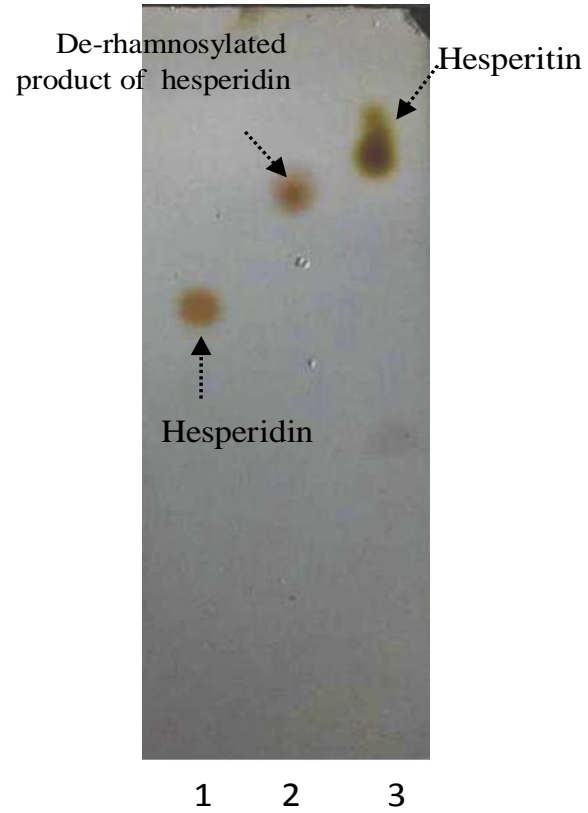


SUNFIRE C-18, $250 \times 4.6,5$ um

17 EAUG 16.49 (1.651)Cm(45.51-(42+55))

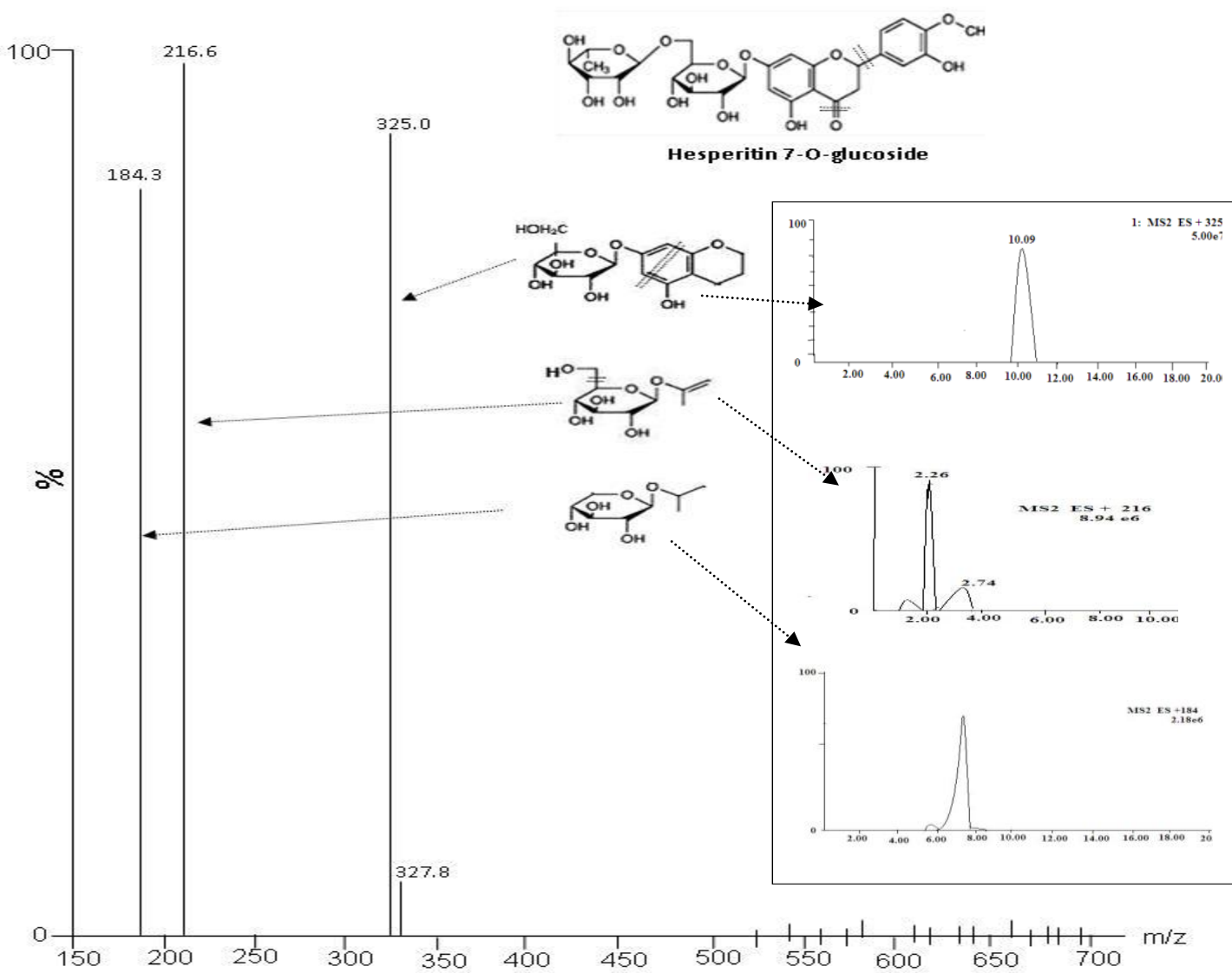

Fig.7 Studies on the release of L-rhamnose from hesperidin by the purified enzyme: (a) Lane 1 pure L-rhamnose and lane 2 released L-rhamnose from hesperidin by enzymatic the enzymatic hydrolysis. (b)) HPLC-MS chromatogram of L-rhamnose from hesperidin by enzymatic the enzymatic hydrolysis

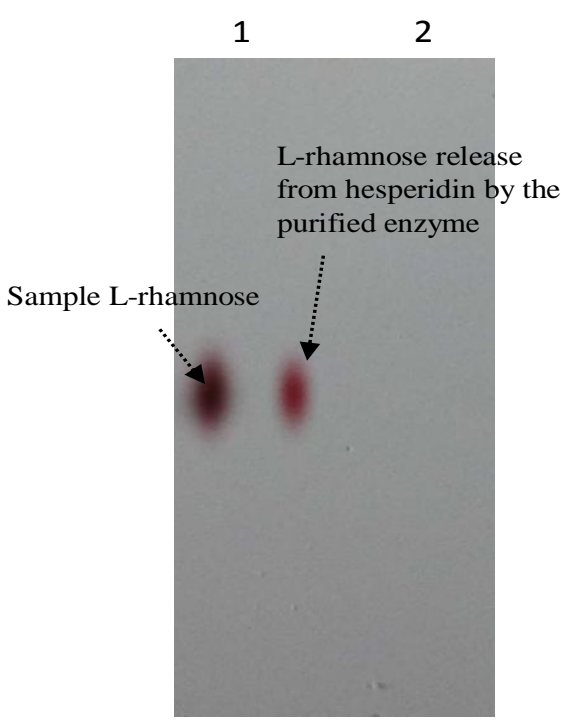




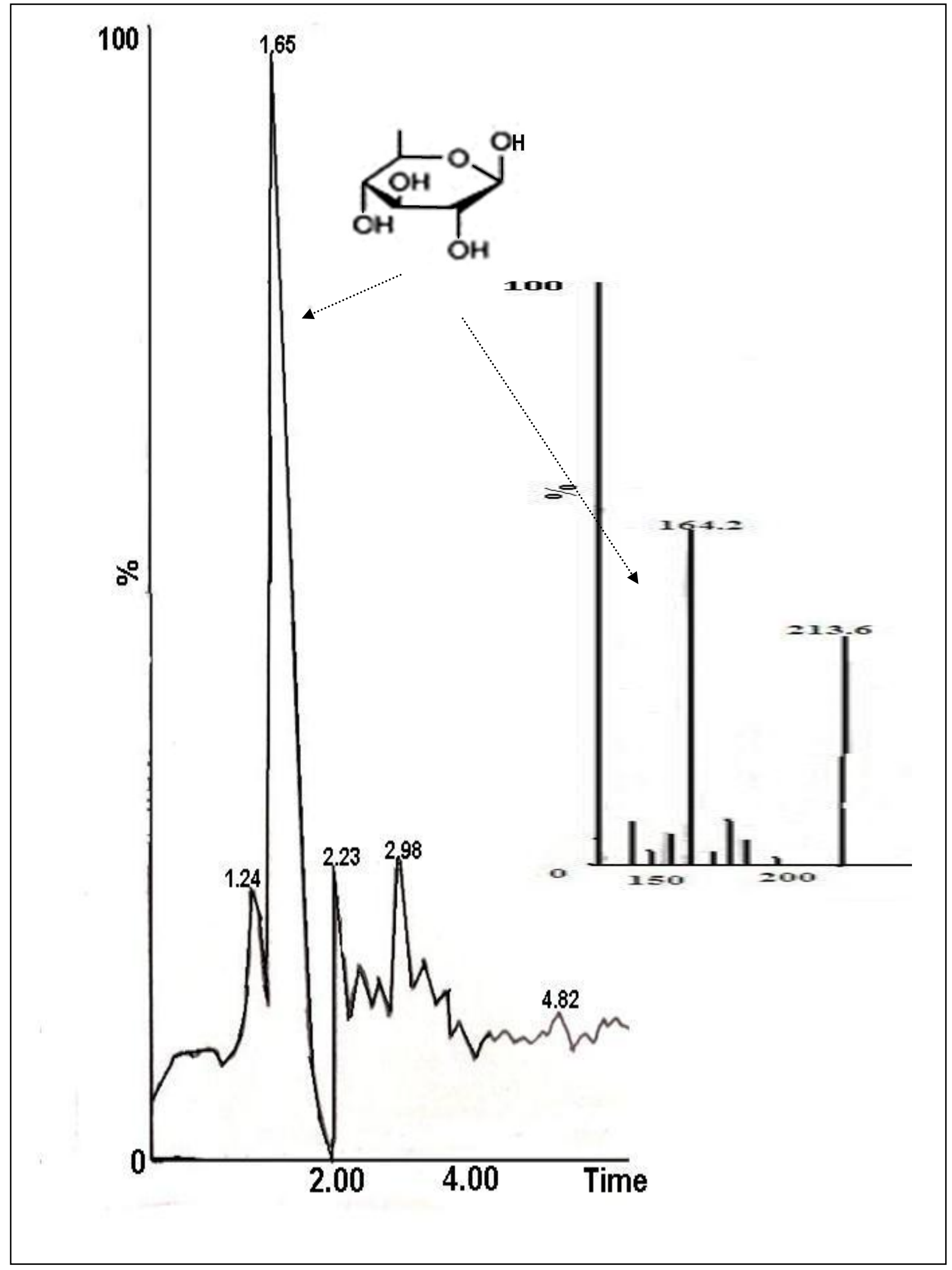


Scheme.1 The de-rhamnosylation of hesperidin to hesperetin 7-O-glucoside by the $\alpha$-Lrhamnosidase

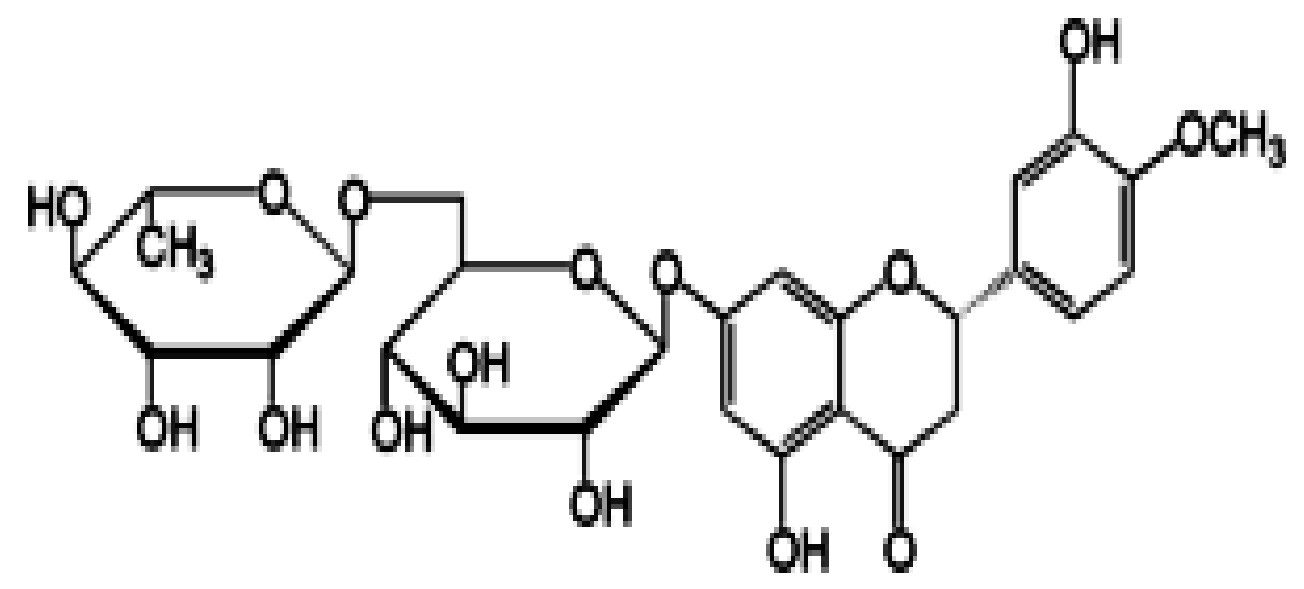

Hesperidin (Hesperetin-7-O-rhamno glucoside)
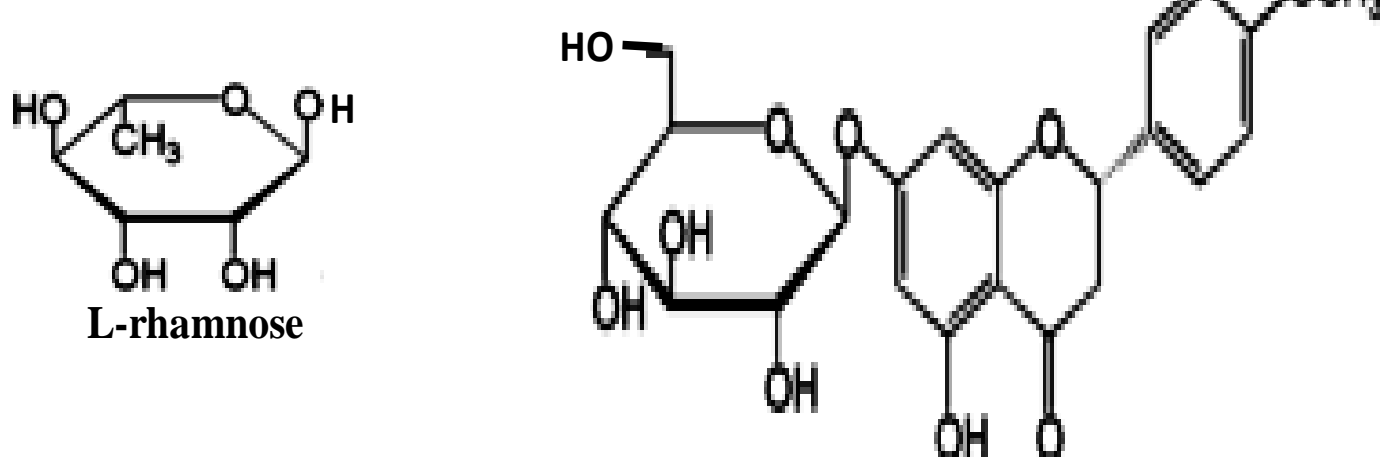

Hesperetin-7-0-glucoside

Scheme - 1- De rhamnosylation of hesperidin to hesperetin- 7-0-glucoside by the $\alpha$-L-rhamnosidase 
The most of the $\alpha$-L-rhamnosidases reported so far have $p H$ optima either in the acidic (Kaji and Ichimi, 1973; Feng et al., 2007) or in neutral (Qian et al., 2005; Zverlov et al., 2000) $p H$ ranges. Only $\alpha$-L-rhamnosidases of Clostridium stercorarium (Hashimoto and Murata, 1998), Sphingomonas paucimobilis (Birgisson et al., 2004), Pseudomonas paucimobilis FP2001 and bacterium PRI1686 (Yadav et al., 2011) have their $p H$ optima values of 7.5, 8.0, 7.9 and 7.8, respectively.

Thus, the purified enzyme is one of a few $\alpha$ L-rhamnosidases which have a $\mathrm{pH}$ optimum 10.0. The $\mathrm{pH}$ stability of the purified in the pH range (De-Silva et al., 2013; Valentova et al., 2014; Miyake and Yumoto, 1999; Manzanares et al., 2003; Chang et al., 2011; Wang et al., 2015; Makino et al., 2009) was also studied. The results is shown in Figure $4 \mathrm{~b}$. The enzyme had maximum stability at $\mathrm{pH}$ 10.0 .

The variation of the activity of the purified enzyme with temperature of the reaction solution is shown in the Figure 5a. The temperature optimum of the enzyme was $50^{\circ} \mathrm{C}$. The temperature optima of the $\alpha-\mathrm{L}$ rhamnosidases reported in the literature (Yadav et al., 2010) were in the range 40$80^{\circ} \mathrm{C}$. The results of the thermal stability studies of the purified $\alpha$-L-rhamnosidase are shown in Figure 5b. The enzyme is stable below $10^{\circ} \mathrm{C}$ but it starts loosing activity as the temperature is increased above $10^{\circ} \mathrm{C}$. The activation energy for the thermal denaturation of the purified enzyme has also been determined and was found to be $26.06 \mathrm{~kJ}$ $\mathrm{mol}^{-1}$. The energy of activation for thermal denaturation of the purified enzyme is in the same range as reported for the $\alpha-\mathrm{L}$ rhamnosidases of $P$. citrinum MTCC-8897, $23.56 \mathrm{~kJ} \mathrm{~mol}^{-1}$ (Yadav et al., 2012) and $\alpha-\mathrm{L}-$ rhamnosidases of $P$. citrinum MTCC-3565, $29.09 \mathrm{~kJ} \mathrm{~mol}^{-1}$ (Yadav et al., 2012) and is lower than the value $35.65 \mathrm{~kJ} \mathrm{~mol}^{-1}$ reported for $\alpha$-L-rhamnosidases of A. awamori MTCC2879 (Yadav et al., 2013).

Suitability of purified enzyme for derhamnosylation of hesperidin

In order to test the suitability of the purified enzyme for de-rhamnosylation of natural glycosides to produce L-rhamnose and pharmaceutically important de-rhamnosylated products, the de-rhamnosylation of naringin, rutin and hesperidin were tested. The purified enzyme did not de-rhamnosylate naringin and rutin but it de-rhamnosylated hesperidin to hesperetin glucoside and L- rhamnose. Figure 6a contains the chromatograms of standard sample of hesperidin, enzyme treated hesperidin solution and standard solution of aglycon of hesperidin, hesperitin. All the three have different Rf values. The enzymatic transformation product of hesperidin $R f$ value (0.74) is not the aglycon of hesperidin, hesperetin $R f$ value (0.80). The result indicates that the enzymatic transformation product of hesperidin $R f$ value (0.59) is hesperetin glucoside $R f$ value (0.74). Further confirmation of hesperetin glucoside is provided by the HPLC-mass spectrometric studies of the enzymatic transformation product of hesperidin. Hesperetin glucoside formed in the enzymatic hydrolysis solution of hesperidin was purified by preparative TLC on silica gel plates. The purified hesperetin glucoside was subjected to HPLCmass spectrophotometric studies. The results are shown in Figure 6b. The presence of characteristic fragments of hesperetin glucoside in mass spectrophotometric studies has confirmed the identity of hesperitin glucoside, the product. The chromatogram of the enzymatic hydrolysis solution of hesperidin done for the purpose of identifying the librated L- rhamnose is shown in Figure 7a. In this figure lane 1 contains the spot of the standard sample of L-rhamnose and lane 2 
contains spot of the librated product. The $R f$ value of the product (0.49) is same as the $R f$ value (0.49) of standard sample of Lrhamnose indicating that the product is $\mathrm{L}$ rhamnose. The identity of the product has again been confirmed by HPLC-mass spectrometric studies of the product purified by TLC. The result is shown in Figure $7 b$. The presence of molecular ion peak at $\mathrm{m} / \mathrm{z}=$ 164 confirms the identity of L-rhamnose.

This communication reports an alkali resistant $\alpha$-L-rhamnosidase which selectively derhamnosylates hesperidin to hesperetin-7-Oglucoside, a pharmaceutically important, bioavailable rare compound of medicinal and food value.

\section{Acknowledgements}

Prof. KDS Yadav and Sudha Yadava acknowledge the financial support of UGC in the form of a major research project No. 37134/2009(SR). Dr. Sarita Yadav acknowledges the financial support of UGC, New Delhi in the form of a Post-Doctoral Fellowship for Women no. PDFWM-201415-OB-UTT-23606 and Dhirendra Kumar acknowledges the financial support of UGCRGNF-2015-17-SC-UTT-2110/(SA-III).The authora are thankful to the incharge Sophisticated Analytical Instrument centre, CDRI, Lucknow, U.P., India for HPLCMasspectrometric analysis.

\section{References}

Arnol FH and Georgiou G, eds. Directed enzyme evolution: library creation. Methods and protocols; Humana press: Totowa, New Jersey, 2003.

Arnol FH and Georgiou G, eds. Directed enzyme evolution: screening and selection methods; Humana press Totowa, New Jersey, 2003.

Bang SH, Hyun YJ, Shim J, Hong SW, Kim DH. Metabolism of rutin and poncirin by human intestinal microbiota and cloning of their metabolizing $\quad \alpha$-L-rhamnosidase from Bifidobacterim dentum. J Microbiol Biotechnol. 2015; 25: 18-25.

Berg JM, Tymoczko JL, Stryer L. Biochemistry, Seventh International edition. WH Freeman and Company: New York, 2012: pp 243.

Birgisson H, Hreggvidsson GO, Fridjo' nsson $\mathrm{OH}$, Mort A, Kristja' nsson JK Mattiasson B. Two new thermostable $\alpha$-L-rhamnosidases from a novel thermophilic bacterium. Enz Microb Technol. 2004; 34: 561-571.

Bourbouze R, Perchekon F, Courtois JE. $\alpha$-LRhamnosidase from Fagopyrum sculentum: Purification and Some Properties. Eur J Biochem. 1976; 63(2): 331-37.

Catalogue of strain, Published by MTCC Center and Gene Bank, Indian Institute of Microbial Technology Chandigarh, 2000.

Celiz G, Rodrriguez J, Soria F, Daz H. Synthesis of Hesperitin-7-O-glucoside from flavonoids extracted from citrus waste using both free and immobilized $\alpha$-L-rhamnosidases. Biocat Agri Biotechnol. 2015 4: 335-341.

Chang HY, Lee YB, Bae HA, Huh JY, Nam SH, et al., Purification and characterization of Aspergillus sojae naringinase: the production of prunin exhibiting markedly enhanced solubility with in vitro inhibition of HMGCoA reductase. Food Chem. 2011; 124(1): 234-241

De-Silva CMG, Contesini FJ, Sawaya ACHF, Cabral EC et al., Enhancement of antioxidant activity of orange and lime juices by flavonoid enzymatic deglycosylation, Food Res. Int. 2013; 52(1): 308-314.

Feng $\mathrm{B}, \mathrm{Hu} \mathrm{W}, \mathrm{Ma} \mathrm{B}$, et al., Purification, characterization, and substrate specificity of a glucoamylase with steroidal saponinrhamnosidase activity from Curvularia lunata. Appl Microbiol Biotechnol. 2007; 76: 1329-1338.

Gerstorferova D, Fliedrova B, Halada P, Marhol, Kren V, Weignerova L. Recombinant $\alpha$-Lrhamnosidase from Aspergillus terreus in selective trimming of rutin. Process Biochem. 2012; 47(5): 828-835.

Hashimoto W, and Murata K. $\alpha$-L-rhamnosidase of Sphingmonas sp. R1 producing an unusual exopolysaccharide of sphingan. Biosci, Biotechnol Biochem. 1998; 62: 1068-1074. 
Hashimoto W, Nankai H, Sato N, Kawai S, Murata K. Characterization of $\alpha$-Lrhamnosidase of Bacillus sp. GL1 responsible for the complete de-polymerization of gellan. Arch Biochem Biophy. 1999; 368: 56-60.

Jang IS and Kim DH. Purification and characterization of $\alpha$-L-rhamnosidase from Bacteroides JY-6, a human intestinal bacterium. Bio Pharma Bul. 1996; 19: 15461549.

Kaji A, and Ichimi T. $\alpha$-L-Rhamnosidase activity in culture filtrate of Corticium rolfsii enzymic activity at low pH. Agri Biol Chem. 1973; 37(2): 431-432.

Kumar A, Singh M K, and Amena S. Optimization of naringinase production and its purification from Micrococcus sp. In $J$ of Pharm Pharma Sci. 2015; 7(2): 269-272.

Kurosawa Y, Ikeda K, Egami F. $\alpha$-Lrhamnosidases of the liver of Turbo cornutus and Aspergillus niger. J Biochem; 1973: 73, 31-37.

Lee YS, Huh JY, Nam SH, Moon SK, Lee SB. Enzymatic bioconversion of citrus hesperidin by Aspergillus sojae naringinase: Enhanced solubility of hesperetin-7-O-glucoside with in vitro inhibition of human intestinal maltase, HMG-CoA reductase, and growth of Helicobacter pylori. Food Chem. 2012; 135(4): 2253-2259.

Lise FD, Mensitieri F, Tarallo V, Ventimiglia N, Vinciguerra R, Tramice R, Pizzo E, Notomista E, Cafaro V, Molinaro A, Birolo L, Donato AD and Lizzo V. RHA-P Isolation, expretion and characterization of a bacterial $\alpha$-L-rhamnosidase from Novosphingobium sp. PP1Y. J Mol Cat B: Enzymatic, 2016; 134:136-147.

Lowry OH, Rosebrough NJ, Farrand AL, Randall RJ. Protein measurement with the folinphenol reagent. J Biol Chem. 1951; 193: 265275.

Makino T, Shimizu R, Kanemaru M, Suzuki Y, Moriwaki M, Mizakami H. Enzymatic modified isoquercitrin, $\alpha$-oligoglycosyl quercetin-3-O-glucoside is absorbed more easily than other quercetin glucoside or aglycon after oral administration in rats. Biol Pharma Bul. 2009; 32: 2034-2040.

Manazanaes P, Vales S, Ramon D, Orejas M. $\alpha$-LRhamnosidase: old and new insights. In:
Polaina J, MacCabe AP, editors. Industrial enzymes. Berlin-Heidelberg: Springer Verlag; 2007. 117-40.

Manzanares P, Broeck HCV, Graaff LHD, Visser J. Purification and characterization of two different $\alpha$-L-Rhamnosidases, RhaA and RhaB from Aspergillus aculeatus. Appl Environ Microbiol. 2001; 67: 2230-2234.

Manzanares P, Orejas M, Gil JV, Graaff LH, Visser J, Ramon D. Construction of a genetically modified wine yeast strain expressing the Aspergillus aculeatus rhaA gene, encoding an a-L-Rhamnosidase of enological interest. Appl Environ Microbiol. 2003; 69: 7558-7562.

Manzanares P, Orejas M, Gil, JV, Graaff L.H, Visser $\mathbf{J} \&$ Ramon D. Construction of a genetically modified wine yeast strain expressing the Aspergillus aculeatus rhaA gene, encoding an $\alpha$-L-rhamnosidase of enological interest. Appl Environ Microbiol. 2003; 69: 7558-7562.

Masuka N, and Kuba I. Characterization of antioxidant activity of flavonoid. Food Chem. 2012; 131: 541-545.

Miake F, Satho T, Takesue H, Yanagida F, Kashige N, Watanabe K. Purification and characterization of intracellular $\alpha$-Lrhamnosidase from Pseudomonas paucimobilis FP 2001. Arch Microbiol. 2000; 173: 65-70.

Miyake T, and Yumoto T. Enzyme treated hesperidin, process for producing the same and method for using enzyme. US Patent. 1999; 5: 885-969.

Monti D, Pisvejcova A, Kren V, Lama M, Riva S. Generation of an a-L-rhamnosidase library and its application for the selective derhamnosylation of natural products. Biotechnol Bioeng. 2004; 87(6):763-71.

O'Neill EC, Stevensom CEM, Peterson MJ,, Rajzek M, Chauvin AL, Lawson DM, Field RA. Crystal structure of a novel two domain GH 78 Family $\alpha$-L-rhamnosidase from Klebsiella oxytoca with rhamnose bound. Protein Structure Function and Bioinformat. 2015; 83:1742-1749.

Park S, Kim J, Kim D. Purification and characterization of quercitrin-hydrolyzing $\alpha$ $\mathrm{L}$ - rhamnosidase from Fusobacterium $\mathrm{K}$-60, 
a human intestinal bacterium. J Microbiol Biotechnol. 2005; 15:519-524.

Pharmacia FCAB. Ion exchange chromatography; principle and methods. Box, 175, S-75104. Pharmecia F.C.A.B. Uppsala, Sweden; 1983.

Qian S, Yu H, Zhang C, Lu M, Wang H, Jin F. Purification and characterization of dioscin- $\alpha$ -L-rhamnosidase from pig liver. Chem Pharma Bul. 2005; 53: 911-914.

Rabausch U, IImberger N, Streit WR. The metagenome-drived enxyme Rha B opens a new sub class of bacterial $B$ type $\alpha-\mathrm{L}-$ rhamnosidase.Jof Biotechnol. 2014; 191:3845.

Romero, C., Manjon, A., Bastida, J. \& Iborra, J.L. (1985). A method for assaying rhamnosidase activity of naringinase. Anal Biochem.1985; 149: 566-571.

Shimoda K, and Hamada H. Production of hesperitin-glucosides by Xanthomonas compestus and Cyclodextrin glucanotransferase and their anti-allergic activities. Nutri. 2010; 2:171-180.

Valentova K, Vrba J, Bancirova M, Ulrichova J, Kren V. Isoquercitrin: pharmacology, Toxicology, and metabolism, Food Chem Toxicol. 2014; 68: 267-282.

Wang J, Gang A, Gu S, Cui $\mathrm{H}$, and $\mathrm{Wu} \mathrm{X}$. Ultrafast synthesis of isoquercitrin by enzymatic hydrolysis of rutin in a continuousflow micro reactor. J Serb Chem. Soc. 2015; 80 (7): 853-866.

Wang J, Gong A, Yang CF, Bio Q, Shi XY, Han $\mathrm{B}, \mathrm{Wu} \mathrm{XY}, \mathrm{WU}$ FA. An effective biphasic system accelerates hesperidinase - catalyzed conversion of rutin to isoquercitrin. Sci Rep. 2015; 5: 86821-5.

Weber K, and Osborn M. The reliability of molecular weight determination by dodecyl sulfate-polyacrylamide gel electrophoresis. $J$ Biol Chem. 1969; 244: 4406-4412.

Yadav S, Yadav V, Yadava S, Yadav KDS. Purification, characterization and application of $\alpha$-L-rhamnosidase from Penicillium citrinum MTCC-8897. I J Food Sci Technol. 2012; 47: 290-298.

Yadav S, Yadav V, Yadava S, Yadav KDS. Purification, characterization and application of $\alpha$-L-rhamnosidase from Penicillium citrinum MTCC-3565. I J Food Sci Technol. 2012; 47: 1404-1410.

Yadav S, Yadava R S S Yadav KDS. Purification and characterization of $\alpha$-L-rhamnosidase from Aspergillus awamori MTCC 2879. I J Food Sci Technol. 2013; 48: 927-933.

Yadav S, Yadava S, Yadav KDS. Purification and characterization of $\alpha$-L-rhamnosidase from Penicillium corylopholum MTCC-2011. Process Biochem. 2013; 48(9): 1348-1354.

Yadav V, Yadav PK, Yadav S, Yadav KDS. $\alpha$-LRhamnosidase: a review. Process Biochem 2010; 45:1226-35.

Yadav V, Yadav S, Yadav S, Yadav KDS. $\alpha$-LRhamnosidase from Aspergillus clavatonanicus MTCC-9611 Active at Alkaline $\mathrm{pH}$. Appl Biochem Microbiol. 2012; 48: 295-301.

Yadav V, Yadav S, Yadava S. Yadav KDS. $\alpha$-LRhamnosidase from Aspergillus flavus MTCC-9606 isolated from lemon fruit peel. $I$ J Food Sci Technol. 2011; 46: 350-357.

Zhu Y, Jia H, Xi M, Xu L, Wu S, Li X. Purificationand characterization of naringenase from a newly isolated strain of Bacillus amyloliquefaciens 11568 suitable for the transformation of flavonoids. Food Chem. 2017; 214:39-46.

Zverlov VV, Herte LC, Bronnenmeier K, Hroch A, Kellermann J, Schwarz WH. The thermostable $\alpha$-L-rhamnosidase RamA of Clostridium stercorarium: biochemical characterization and primary structure of a bacterial $\alpha$-L-rhamnoside hydrolase, a new type of inverting glycoside hydrolase. Mol Microbiol. 2000; 35:173-179.

\section{How to cite this article:}

Sarita Yadav, Dhirendra Kumar, Sudha Yadava and Yadav, K.D.S. 2018. De-rhamnosylation of Hesperidin to Hesperitin-7-O-Glucoside by Alkali Tolerant $\alpha$-L-rhamnosidase from Fusarium poae MTCC-2086. Int.J.Curr.Microbiol.App.Sci. 7(03): 1952-1968.

doi: https://doi.org/10.20546/ijcmas.2018.703.231 